IN the spring of I885, at Divonne-les-Bains, I killed a snake, and on cutting it open I found one frog slightly decomposed and another frog apparently dead; the latter recovered in about a quarter of an hour, and hopped away.

32 Prescot Street, Halifax, August 12.

\section{Dogmatism on the Moon and the Weather.}

IN a recent little book, "The Story of the Weather," by G. F. Chambers, I have come across one of those ex cathedrit statements which, I think, illustrate the curious disposition of the mind (even the scientific mind) to circumscribe and limit truth. "No one in his senses," our Meteorological Office is quoted as saying, "can believe in the moon's influence on the weather." Is the matter, then, clear as noonday, or as an axiom of mathematics? Supposing we have, thus far, no proof of such influence, how can we possibly be certain that no such influence exists, or will ever be demonstrated? 'I happen to be, unfortunately, one of those "lunatics"; but I rather think I am in good com pany. The author of the book himself, oddly enough, just before approving, apparently, the above dictum, expresses his firm conviction (p. I 97) that the full moon scatters clouds (a point, however, which I cannot say I have studied).

A. B. M.

\section{Rules for Compositors and Readers.}

In the British Printer for May and June of last year appears an article under the above heading, by Mr. Horace Hart, Controller, Clarendon Press, Oxford, which, as in my case, may have escaped the notice of some of your readers. On this assumption it would be as well, taking into consideration the importance of the matter to scientific men generally and directors of museums in particular, to ask for the views of others qualified to judge upon the advisability of discarding the use of the digraphs $\propto$ and $\propto$ in Greek words written in English characters, in Latin words, and-presumably -in words derived therefrom, such as Coelenterata and Caesarean, which, according to Mr. Hart, should not be written, as they usually are, Crelenterata and Caesarean. The importance of such a ruling cannot be over-estimated in any museum which desires to teach and not mislead its students--to say nothing of the waste of elaborate labels which the disuse of the digraphs entails, and these considerations must be my excuse for troubling your technical readers for their opinions.

Leicester. MONTAGU Browne.

\section{"ARTIFICIAL FOOD."}

GNDER the above title the Daily Chronicle of Friday, August 5, prints a telegram from its Vienna correspondent announcing the synthetic preparation, by Dr. Leon Lilienfeld, of albumen having " absolutely the same nourishing qualities as found in that which is obtained from organic beings." Such a synthesis would undoubtedly mark an epoch both in chemistry and physiology, but unfortunately for those who have attached undue importance to Dr. Lilienfeld's announcement, the data given in the sensational telegrams, if correct, were sufficient to show that, whatever be might have achieved he had certainly not obtained the substance commonly known as albumen. It is enough to point out that with the materials employed, the artificial product could not contain sulphur, which, at any rate up to the present, is regarded as an essential constituent of albumen.

The report of the International Congress of Applied Chemistry, given in the number of the Chemiker Zeitung (xxii. 644) just to hand, includes a short account of Dr. Lilienfeld's paper. Translated it runs :-

"Dr. Lilienfeld gave a very interesting account of the artificial synthesis of albuminous substances (Eizereisskörper). It has been found possible to prepare pepton hydrochloride by the condensation of phenol and glycocoll with phosphoric oxychloride ; thus obtained, it gives all the reactions of the albuminoids. The lecturer experimentally demonstrated the preparation and properties of the new compound. By previous conversion into the sulphate and decomposition of the latter, the free pepton can be obtained, and resembles, both in its chemical and physiological behaviour, the natural pepton from albumen. The analytical data corresponded with those given by natural pepton."

From this it is evident that Dr. Lilienfeld claims not the synthesis of albumen, but that of pepton, a digestion product of albumen, which, in spite of the statements of Henninger and others, does not seem so far to have been reconverted to its parent substance. In the absence of exact details, it is impossible to say how far the claim to the synthesis of pepton is justified, but it may be as well to recall previous work in the same direction.

Grimaux published in the Comptes rendus, about fourteen years ago, several papers on the formation of colloids from inorganic materials. Amony others he obtained two: (I) by heating meta-amidobenzoic acid with phosphorus pentachloride, and (2) by the action of ammonia on solid aspartic anhydride heated at $170^{\circ}$. Although it was not to be expected that albumen would be obtained from such materials, it is remarkable how close was the resemblance between these colloids and the proteids when judged solely by their reactions.

A little later Schützenberger attempted the synthesis of proteids from the products of their decomposition. He had been engaged for some years on the study of the products of the hydrolytic decomposition of albumen by barium hydrate solution at varying temperatures. Among the substances obtained were various amido-acids of both the fatty and the aromatic series. He therefore dehydrated a mixture of these acids and urea with phosphoric anhydride, hoping thus to reverse the hydration process. Without giving details of the method employed, it is sufficient to say that he obtained a colloid which gave the reactions usually considered diagnostic of a proteid.

In 1897 Dr. J. W. Pickering (in continuation of a series of papers published in conjunction with Prof. Halliburton in the Journal of Physiology) contributed an interesting paper to the Royal Society's Proceedings (NATURE, I 897, 34 I ), in which, besides confirming Grimaux's results, he added many valuable observations of his own. Among the most remarkable of these is the fact that the colloid obtained from aspartic anhydride is digested by pepsin-hydrochloric acid, and then gives the colour reactions for pepton, and, further, that it closely resembles the nucleo-proteids in its physiological action.

Dr. Pickering, moreover, greatly extended Grimaux's work, and prepared several new colloids, such as one from a mixture of tyrosine, biuret, and phosphorus pentachloride, a second from para-amidobenzoic acid and phosphorus pentachloride, and a third from alloxan, meta-amidobenzoic acid and phosphoric anhydride. These, together with several others, gave the reactions of the proteids, coagulated at definite temperatures, and produced intravascular coagulation of the blood. Still more noteworthy is the fact that according to the author they are optically active, like the natural proteids. Should this statement be confirmed, these would be the first optically active substances produced directly from inactive materials. As this feat has hitherto been regarded by chemists as improbable, if not impossible, these colloids are certainly worthy of closer investigation from this point of view.

Dr. Lilienfeld, too, has synthesised a substance giving the reactions of a proteid by condensation of a base which he called biuretdimethylene, with different amidoacids. It should, however, be noted that these workers, so far, have not claimed that the products obtained were actually proteids, but only that they bore a striking resemblance to them; and in this they were doubtless correct.

It is well known that the so-called "tests" applied to the detection of a proteid are purely empirical. Such 